\title{
Coxsackievirus B4 Can Infect Human Peripheral Blood-Derived Macrophages
}

\author{
Enagnon Kazali Alidjinou ${ }^{1}$, Famara Sané ${ }^{1}$, Jacques Trauet ${ }^{2}$, Marie-Christine Copin ${ }^{3}$ \\ and Didier Hober $1, *$
}

Received: 30 September 2015; Accepted: 18 November 2015; Published: 24 November 2015

Academic Editor: George Belov

1 Laboratoire de virologie EA3610, Faculté de Médecine, Université de Lille, CHU de Lille 59037, France; enagnonkazali.alidjinou@chru-lille.fr (E.K.A.); famara.sane@chru-lille.fr (F.S.)

2 Laboratoire d'immunologie, Faculté de Médecine, Université de Lille, CHU de Lille 59037, France; jacques.trauet@chru-lille.fr

3 Laboratoire d'anatomie pathologique, Faculté de Médecine, Université de Lille, CHU de Lille 59037, France; marie-christine.copin@chru-lille.fr

* Correspondence: didier.hober@chru-lille.fr; Tel.: +33-03-20-44-66-88; Fax: +33-03-20-44-48-95

\begin{abstract}
Beyond acute infections, group B coxsackieviruses (CVB) are also reported to play a role in the development of chronic diseases, like type 1 diabetes. The viral pathogenesis mainly relies on the interplay between the viruses and innate immune response in genetically-susceptible individuals. We investigated the interaction between CVB4 and macrophages considered as major players in immune response. Monocyte-derived macrophages (MDM) generated with either M-CSF or GM-CSF were inoculated with CVB4, and infection, inflammation, viral replication and persistence were assessed. M-CSF-induced MDM, but not GM-CSF-induced MDM, can be infected by CVB4. In addition, enhancing serum was not needed to infect MDM in contrast with parental monocytes. The expression of viral receptor (CAR) mRNA was similar in both M-CSF and GM-CSF MDM. CVB4 induced high levels of pro-inflammatory cytokines (IL-6 and TNF $\alpha$ ) in both MDM populations. CVB4 effectively replicated and persisted in M-CSF MDM, but IFN $\alpha$ was produced in the early phase of infection only. Our results demonstrate that CVB4 can replicate and persist in MDM. Further investigations are required to determine whether the interaction between the virus and MDM plays a role in the pathogenesis of CVB-induced chronic diseases.
\end{abstract}

Keywords: coxsackievirus B; monocyte-derived macrophages; M-CSF; GM-CSF; infection; inflammation; persistence; PACS; J0101

\section{Introduction}

Enteroviruses (EV) are small (20-30 $\mathrm{nm}$ ) non-enveloped positive single-strand RNA viruses that belong to the Picornaviridae family. The genus Enterovirus is very important in medicine and includes several major human pathogens. Group B coxsackieviruses (CVB 1-6) are classified within the Human Enterovirus B (HEV-B) species [1,2]. CVB infections are usually mild and asymptomatic, but they can cause severe acute illnesses [2,3]. In addition, accumulating evidence supports a strong association between these viruses and chronic diseases, such as type 1 diabetes (T1D) [4,5]. The virus is thought to trigger autoimmunity in genetically-predisposed individuals through various mechanisms, including activation of inflammation and persistence, and contributes then to the development of the disease [5]. This pathogenesis strongly relies on the response of the immune system and especially the innate immunity to the virus. Therefore, innate immunity cells are believed to play a major role in the orchestration of this process. The interactions between CVB and innate immunity cells are not well understood. 
In T1D patients, EV components have been detected more frequently in peripheral blood mononuclear cells (PBMC) [6-9], and monocytes were shown to harbor the virus [10].

In vitro, monocytes and monocytic cell lines are poorly permissive to CVB. However, these cells can be effectively infected when the virus is previously incubated with non-neutralizing serum or IgGs $[11,12]$. The antibody-dependent enhancement of CVB4 infection results in the production of high amounts of IFN $\alpha$ [11-14] and increased levels of other proinflammatory cytokines [15].

Monocytes are produced from progenitors in the blood marrow and usually circulate via the bloodstream to peripheral tissues. In the steady state or in response to inflammation, monocytes migrate into tissues, attracted by various cytokines or necrotic cells, and mature to replenish resident macrophages and dendritic cells (DC) [16]. Macrophages and DC are well known as potent initiators of immune response. These professional antigen-presenting cells are well equipped with several sensors, namely pattern recognition receptors, and can, on the one hand, initiate and control immune responses to invading pathogens and, on the other, maintain tolerance to self-antigens [17].

Human monocyte-derived DCs can be infected by many viruses [18-21], but were reported to be non-permissive to CVB $[22,23]$.

Macrophages are primarily remarkable phagocytic cells, but they also have a great plasticity that allows them to respond to environmental cues and change their phenotype, depending on the activation state [24]. Macrophages are one of the earliest detectors of danger signals in the host, and their physiology can be highly modified by the mediators of the immune response, especially cytokines. An environmental signal, such as viral infection, can either increase macrophage immune function or give rise to macrophages that are more susceptible to the infection with less antiviral response [24]. Besides being target cells, macrophages could then play a role in the pathogenesis of virus-induced diseases.

In addition to CD8 cytotoxic T lymphocytes, macrophages have been reported to be common in insulitis found in the pancreas of T1D, both at early and later stages of disease progression [25]. Therefore, in the hypothesis of CVB involvement in the pathogenesis of the disease, the role of interactions between macrophages and the virus cannot be ruled out. Such an interaction has not been investigated yet.

In vitro, several viruses can infect monocyte-derived macrophages (MDM) [26-28] with various outcomes, but no study was reported regarding the infection of these cells with CVB.

In this study, we describe the infection of human MDM by CVB4 and further investigate the inflammation induced by the virus, as well as its persistence in these cells.

\section{Results}

\subsection{Monocyte-Derived Macrophages}

Monocytes were cultured for seven days in serum-free medium (SFM) containing either M-CSF or GM-CSF. Under these conditions, on Day 7, the cells appeared roughly similar under the microscope, but they were slightly larger in cultures treated with M-CSF (Figure 1a). The staining with MGG displayed that the cells were similar; however, vacuoles or bi-nucleated cells were more common in M-CSF-treated cultures (Figure 1b). M-CSF and GM-CSF-treated cells were macrophages, as they were stained with CD68 antibody (Figure 1c). The macrophages differentiated under these conditions shared the same pattern of staining as regards various markers: CD163+, CD14+, CD80-, CD83-, CD86+, CCR7+ and HLA-DR+ (Figure 1d,e). 


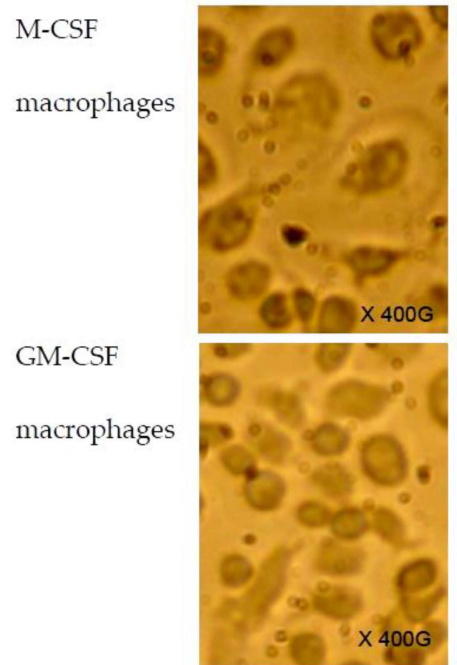

(a)
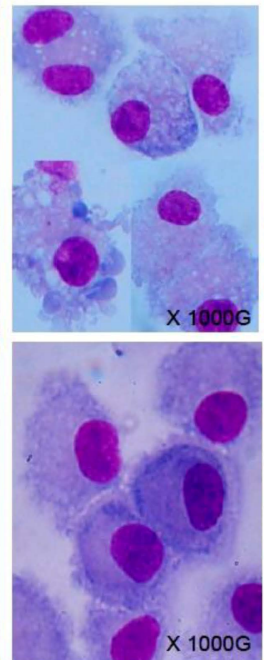

(b)
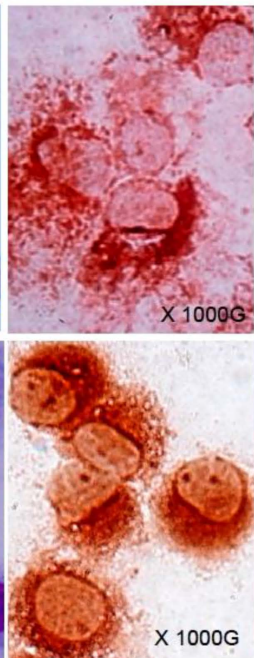

(c)
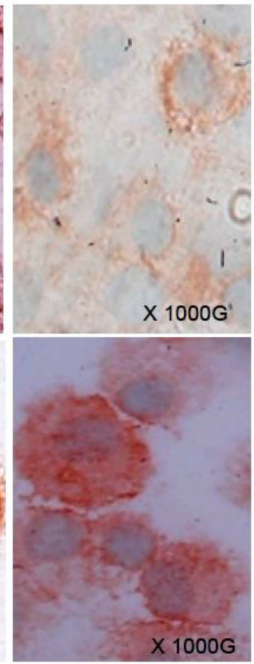

(d)

(e)

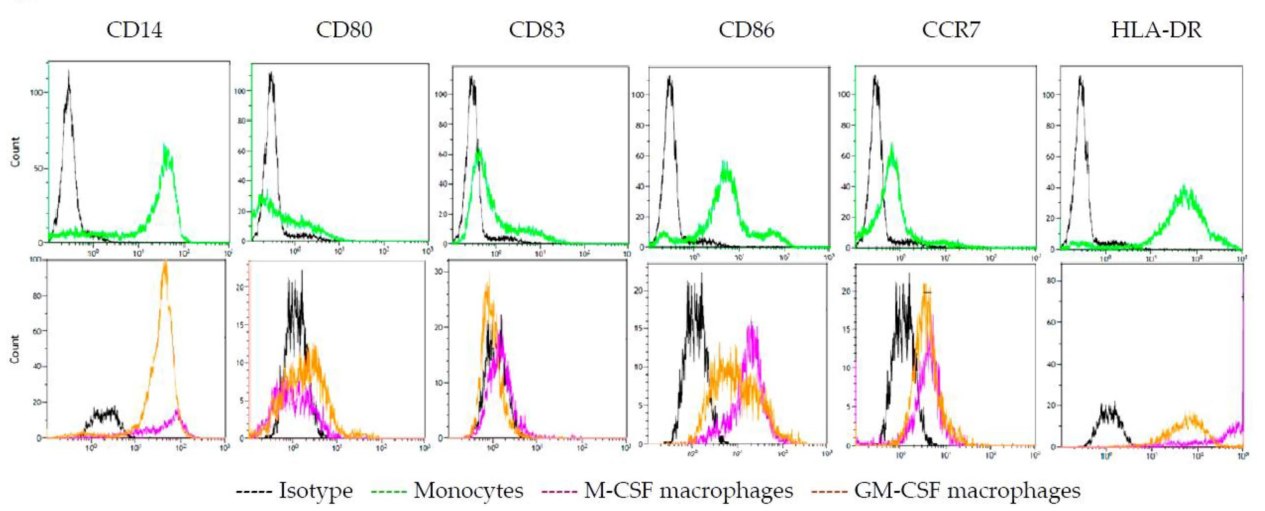

Figure 1. Monocyte-derived macrophages. Monocytes were maintained in serum-free culture medium containing M-CSF or GM-CSF for 7 days. Then cells were directly observed in the culture plate under an inverted microscope (initial magnification X400) (a). Cells were cytocentrifuged on slides and stained with MGG (b) or labeled with anti-CD68 (c) and anti-CD163 (d) antibodies by immunocytochemistry (initial magnification X1000). Parental monocytes and derived macrophages were collected and analyzed by flow cytometre (e). These observations are representative of three independent experiments.

\subsection{CVB4 Can Infect M-CSF-Treated Cells, but not GM-CSF-Treated Cells}

Monocytes and monocyte-derived macrophages were inoculated with CVB4 or CVB4 mixed with non-neutralizing dilutions of human serum. In all of the experiments of this study, the multiplicity of infection (MOI) was one. The cultures were incubated; then, 24 and $72 \mathrm{~h}$ post-infection (pi), supernatants were collected for IFN $\alpha$ quantification, and the cells were washed five times with PBS and used for viral RNA quantification. As shown in Figure 2, monocytes did not produce IFN $\alpha$ when they were inoculated with CVB4. However, production of IFN $\alpha$ was obtained when the cells were inoculated with CVB4 mixed with diluted human serum (1/100 dilution); the levels of IFN $\alpha$ reached $462 \pm 174 \mathrm{pg} / \mathrm{mL}$ and $443 \pm 203 \mathrm{pg} / \mathrm{mL}$ at $24 \mathrm{~h}$ and $72 \mathrm{~h}$ pi, respectively, with an interindividual variability (Figure 2a). When M-CSF-treated cells were inoculated with CVB4, no IFN $\alpha$ was detected in the supernatant collected $24 \mathrm{~h}$ pi, whereas a significant amount of IFN $\alpha$ was detected $72 \mathrm{~h}$ pi $(190 \pm 51 \mathrm{pg} / \mathrm{mL})$. There was no IFN $\alpha$ in the supernatants of cultures inoculated with CVB4 mixed with human serum (1/100 dilution), but the level was $188 \pm 53 \mathrm{pg} / \mathrm{mL}$ in supernatants of cultures inoculated with CVB4 mixed with 1000-fold diluted human serum (Figure 2a) and was similar to further dilutions of human serum. Regarding GM-CSF-treated cells, no IFN $\alpha$ was 
detected in supernatants, whether CVB4 was previously incubated or not with diluted human serum (Figure 2a). IFN $\alpha$ was not detected in supernatants from control cell cultures.
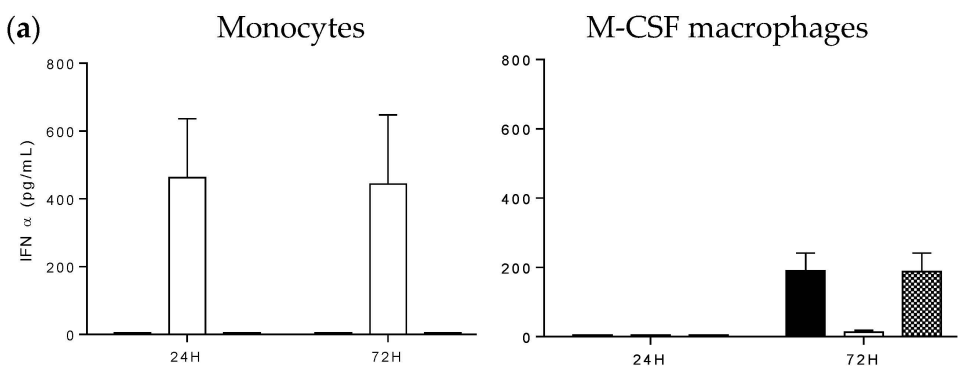

GM-CSF macrophages
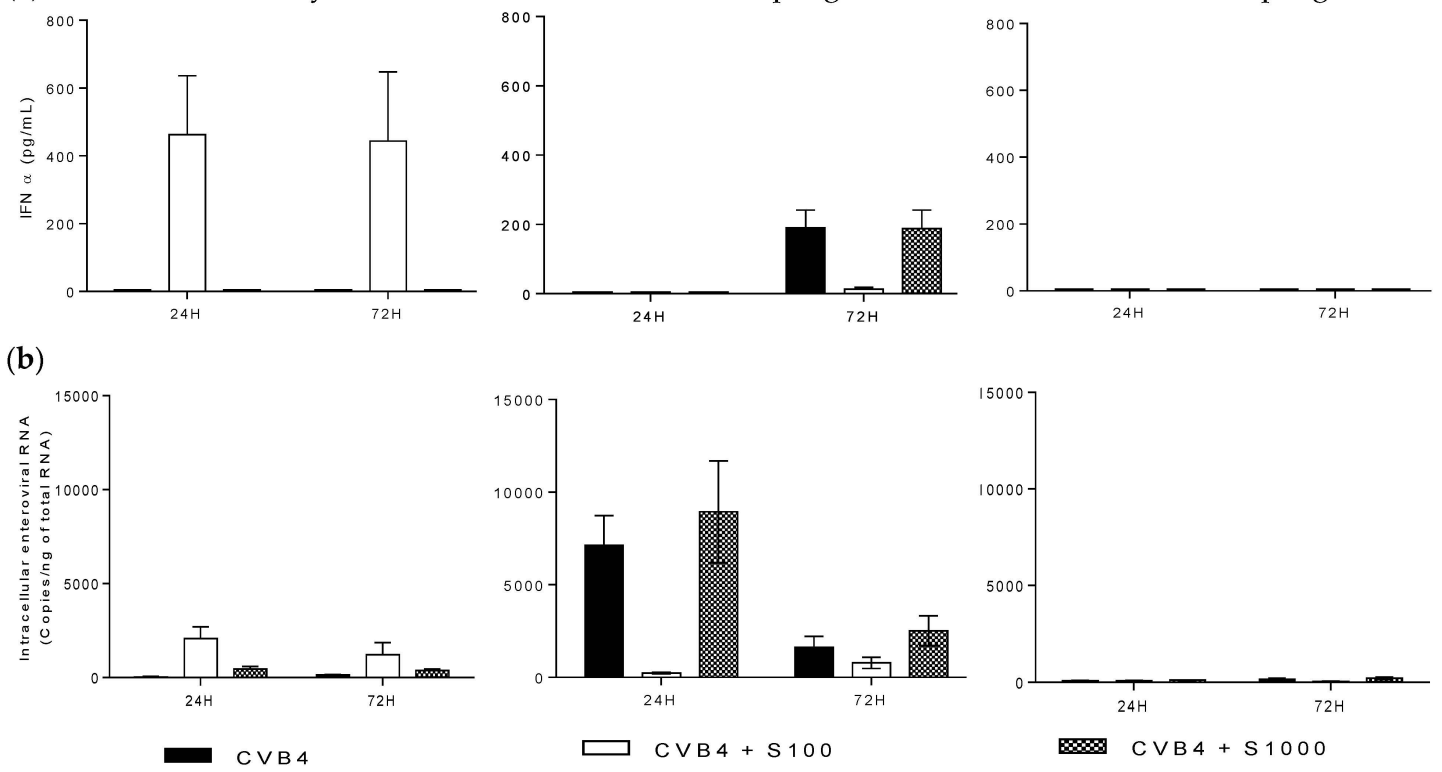

Figure 2. Group B coxsackieviruses 4 (CVB4) can infect M-CSF-induced monocyte-derived macrophages. Monocytes and monocytes treated with M-CSF or GM-CSF for seven days (M-CSF macrophages and GM-CSF macrophages) were inoculated with CVB4 or CVB4 mixed with diluted anti-CVB4 human serum (S100: 1/100 dilution, S1000: 1/1000 dilution). The cell cultures were incubated for $24 \mathrm{~h}$ and $72 \mathrm{~h}$, then IFN $\alpha$ levels in the supernatants were measured by using ELISA (a), and intracellular viral RNA was quantified by using real-time RT-qPCR (b). These results are the mean \pm SEM of three independent experiments.

As far as the quantification of intracellular enteroviral RNA was concerned, the levels were very low in monocytes inoculated with CVB4, $85 \pm 47$ and $146 \pm 68$ copies/ng of total RNA at 24 and $72 \mathrm{~h}$ pi, respectively, and increased significantly when monocytes were inoculated with CVB4 mixed with 100-fold diluted human serum, reaching $2070 \pm 626$ and $1215 \pm 645$ copies/ng of total RNA at 24 and $72 \mathrm{~h}$, respectively (see Figure 2b). In M-CSF-treated cells infected with CVB4, the levels of viral RNA $(7126 \pm 1609$ and $1623 \pm 601$ copies/ng of total RNA at 24 and $72 \mathrm{~h}$ ) were high. There was no significant increase when the cells were inoculated with CVB4 mixed with 1000-fold diluted human serum (8939 \pm 2753 and $2514 \pm 801$ copies/ng of total RNA) (Figure 2b). In contrast, viral RNA was almost undetectable in GM-CSF-treated cells inoculated with CVB4 or CVB4 mixed with human serum (Figure $2 \mathrm{~b}$ ). No virus was detected in control cell cultures.

Altogether, these results show that CVB4 can infect MDM differentiated in culture medium containing M-CSF and that there is no human serum-dependent enhancement of CVB4 infection of these cells. In contrast, MDM differentiated in culture medium containing GM-CSF were not permissive to CVB4.

We hypothesized that GM-CSF-induced MDM were not permissive to CVB4, compared to M-CSF-induced MDM, because of a reduced expression of CAR, the receptor for CVB4. CAR mRNA was then quantified in both cell populations collected after differentiation on Day 7. As shown in Figure 3, the relative expression of CAR was similar in GM-CSF-induced and M-CSF-induced MDM. 


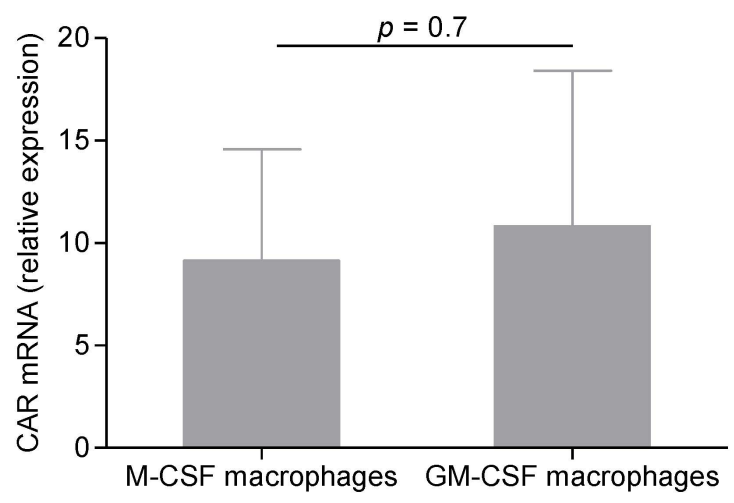

Figure 3. CAR mRNA expression in macrophages. Monocytes and MDM treated with M-CSF or GM-CSF for seven days were collected, and RNA was extracted. CAR mRNA and $\beta$-actin were amplified using real-time RT-PCR. CAR relative expression was determined using the $2^{-\Delta \Delta C t}$ formula, as compared to parental monocytes. These results are the mean \pm SEM of three independent experiments.

\subsection{CVB4 Can Induce Pro-Inflammatory Cytokines MDM Induced with M-CSF and GM-CSF}

We previously observed that PBMCs were not infected when they were inoculated with CVB4; nevertheless, they can produce high levels of pro-inflammatory cytokines [15]. Therefore, the production of these cytokines in MDM cultures was investigated. Cell cultures were inoculated with CVB4, as described above, and supernatants were collected at 24 and $72 \mathrm{~h}$ pi. Like monocytes, both M-CSF- and GM-CSF-induced MDM produced high levels of IL-6, up to $3000 \mathrm{pg} / \mathrm{mL}$ in both cell cultures (Figure 4a). CVB4 also induced significant amounts of TNF $\alpha$ in both cell cultures (up to 1200 and 1700 pg/mL in M-CSF- and MG-CSF-induced MDM, respectively) (Figure 4b). On the other hand, CVB4 did not induce any significant production of IL-10 in these cells (Figure 4c). None of these cytokines were detected in control wells.

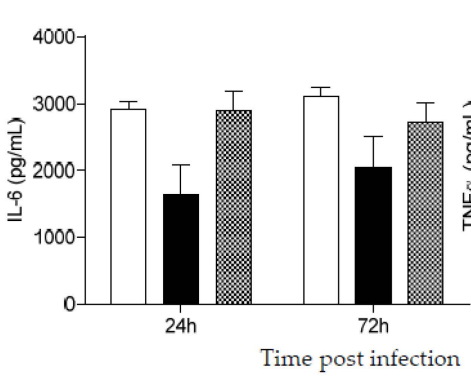

Monocytes (b)

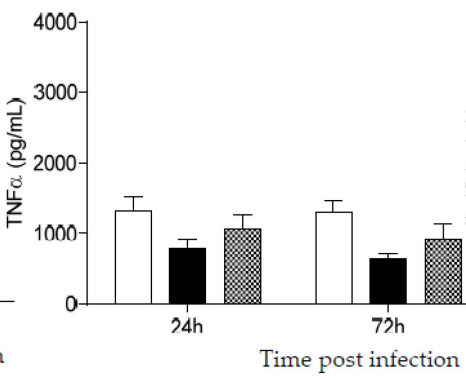

M-CSF macrophages (c)

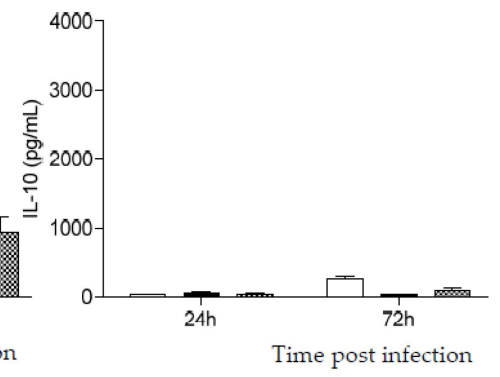

GM-CSF macrophages

Figure 4. CVB4 can induce pro-inflammatory cytokines in monocyte-derived macrophages (MDM). Monocytes and MDM induced with M-CSF (M-CSF macrophages) or GM-CSF (GM-CSF macrophages) for seven days were inoculated with CVB4. Supernatants were collected at 24 and $72 \mathrm{~h}$ post-infection (pi). IL-6 (a), TNF $\alpha$ (b) and IL-10 (c) were measured in supernatants by using ELISA. These results are the mean \pm SEM of three independent experiments.

\subsection{CVB4 Can Replicate and Persist in M-CSF-Induced MDM}

In so far as M-CSF-induced MDM were permissive to CVB4 infection, we investigated further the replication and the persistence of the virus in these cells. MDM were inoculated with CVB4, 
and after $2 \mathrm{~h}$, the cells were extensively washed five times with PBS and then cultured in serum-free medium for 12 days. Supernatants and cells were collected every three days. The viability of cells was assessed during the follow-up (Figure 5a).

High levels of IFN $\alpha$ were detected in supernatants on Day 3 pi. Afterwards, the levels of IFN $\alpha$ decreased dramatically and were almost undetectable on Day 6 pi (Figure $5 b$ ).

The levels of infectious viral particles in supernatants were assessed by $\mathrm{TCID}_{50}$ determination on HEp-2 cells. The viral titers reached a maximum of $8.6 \pm 2 \log \mathrm{TCID}_{50} / 100 \mu \mathrm{L}$ on Day 3 and decreased progressively, but were still around $2.5 \log \mathrm{TCD}_{50} / 100 \mu \mathrm{L}$ on Day 12 (Figure $5 \mathrm{c}$ ).

The RNA viral load in supernatants was correlated with the viral titers. The maximum value was reached on Day 3 pi $(7.4 \pm 0.4 \log$ copies $/ \mu \mathrm{L})$ and was $3.6 \pm 0.2 \log$ copies $/ \mu \mathrm{L}$ on Day 12 (Figure $5 \mathrm{~d}$ ).

Intracellular viral RNA was also detected significantly during the follow-up. The highest levels were around $4 \log$ copies/ng of total RNA and were reached between three and six days pi (Figure 5e).

(a)

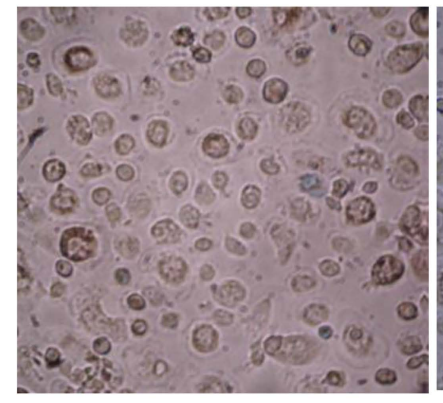

(b)

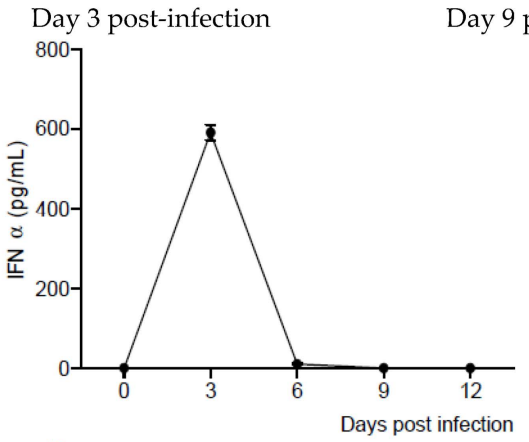

(d)

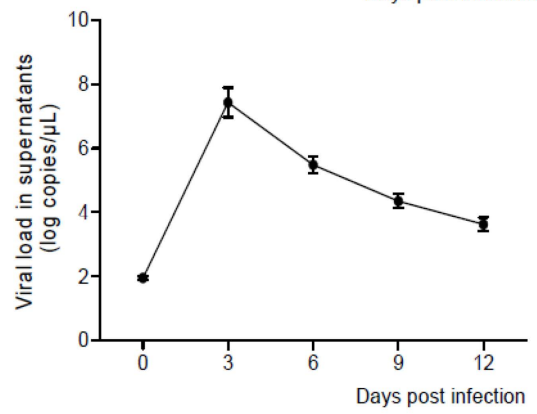

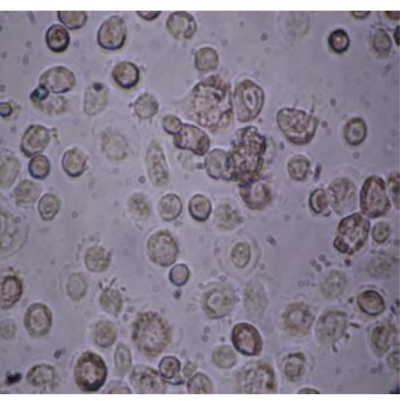

Day 9 post-infection

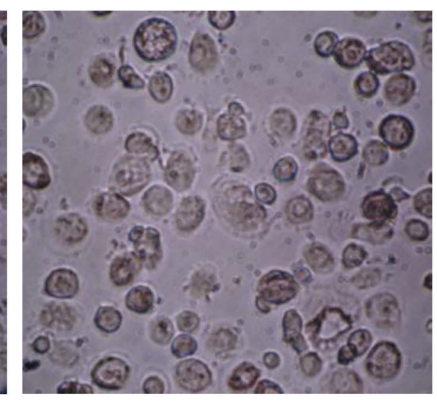

Day 12 post-infection

(c)

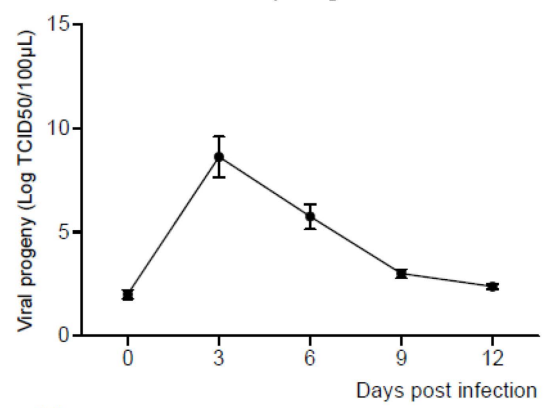

(e)

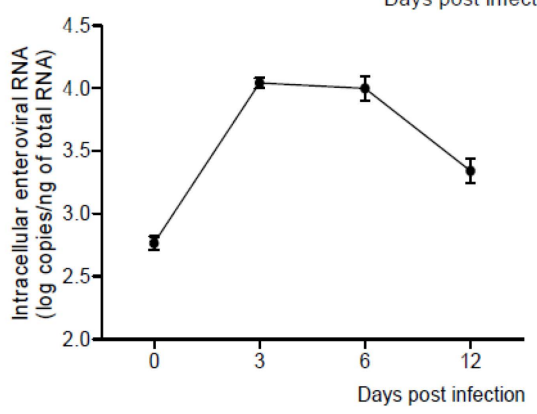

Figure 5. CVB4 can replicate and persist in M-CSF MDM. MDM treated with M-CSF for seven days were inoculated with CVB4 and were cultured for 12 days. The cell viability was assessed using the trypan blue exclusion assay (a). In supernatants, the levels of IFN $\alpha(\mathbf{b})$, infectious particles (c) and enteroviral RNA (d) were determined. In cells, enteroviral RNA was quantified by real-time RT-qPCR (e). These results are the mean \pm SEM of three independent experiments.

\section{Discussion}

In this study, we described, for the first time, the infection of human primary macrophages by group B coxsackieviruses. We demonstrated that CVB4 can effectively infect M-CSF-induced MDM, 
but not GM-CSF-induced MDM. In addition to the production of viral particles, a persistence of viral RNA has been observed in M-CSF-induced MDM cultures.

Previous investigations by our team focused on peripheral blood mononuclear cells (PBMCs) and revealed that among these cells, only monocytes could be infected by CVB in vitro, as well as in vivo [10]. Monocytes are not spontaneously permissive to the virus; however, the infection can be enhanced by antibodies, as described in previous papers [11,13]. The infection of monocytes with CVB4 can be obtained by pre-incubation of the virus with non-neutralizing dilution of an immune serum before inoculation to cells [11,13]. Enhanced CVB infection of monocytes was shown to rely on both the specific receptor CAR and FC $\gamma$ receptors, and the target of enhancing antibodies was reported to be the viral protein VP4 [14,29].

However, monocytes are not long-life cells and usually leave the bloodstream after 2-3 days to reach tissues and differentiate into mature cells, such as macrophages [16]. Therefore, the exploration of the interactions between CVB and these cells highly involved in immune response is needed, in the hypothesis of the involvement of the virus in chronic auto-immune diseases, like T1D.

For in vitro studies on macrophages, several protocols have been described by researchers to differentiate macrophages from blood monocytes, and usually include the use of: (i) media containing human autologous or heterologous $\mathrm{AB}$ serum or fetal bovine serum; or (ii) media containing growth factors, namely M-CSF or GM-CSF [30,31].

In this report, MDM were generated by treating monocytes with a serum-free medium containing either M-CSF or GM-CSF. The phenotypes of cells obtained in both conditions were similar as shown by immunological markers; but surprisingly, only cells treated with M-CSF could be infected by CVB4. It is important to note that the cells were treated for seven days, and then, after washings, they were maintained in culture medium without growth factors. Thus, the opposite patterns of data regarding the infection of MDM in our experiments can be due to some differences between M-CSF-treated cells and GM-CSF-treated cells.

It has been reported that GM-CSF-induced MDM share some transcriptional profiles of classically-activated pro-inflammatory (M1) cells in vivo, while those induced with M-CSF tend to replicate alternatively-activated anti-inflammatory (M2) macrophages [30-32], but such an association is overestimated. M-CSF and GM-CSF MDM share many features, but are also different regarding the expression of some gene markers and some functions [31,33,34]. A more realistic in vitro approach considers MDM generated with M-CSF and GM-CSF as M0 macrophages, and then, M1 originate from M0 induced with GM-CSF or M-CSF in the presence of IFN $\gamma$ and/or LPS, while M2 macrophages are triggered from M-CSF-induced cells by the presence of cytokines, such as IL-4 or IL-10 $[31,35,36]$. In so far as the cells were treated with M-CSF or GM-CSF, but not with additional factors, it can be admitted that MDM were M0 macrophages in our experiments.

The discrepancy observed between M-CSF- and GM-CSF-induced MDM regarding CVB4 infection was not due to a reduced transcriptional expression of the specific viral receptor CAR in GM-CSF-treated cells, as shown by quantitative real-time RT-PCR. It remains to be determined whether the receptor is present at the same level at the surface of both M-CSF and GM-CSF cells. Furthermore, in non-polarized cells, it has been reported that a secondary receptor, such as decay-accelerating factor (DAF), is not mandatory for CVB infection, whereas other entry pathways and molecules seem to be critical for entry [37]. Whether these mechanisms of entry are active in M-CSF-induced MDM, but not in GM-CSF-induced MDM cannot be ruled out.

In this study, it has been observed that CVB4 induced the production of high levels of pro-inflammatory cytokines, such as IL-6 and TN $\alpha$, in both M-CSF MDM and GM-CSF MDM cultures. Since GM-CSF MDM were not infected with CVB4, the production of cytokines was thought to be triggered mainly by surface sensors on these cells, which is in agreement with previous studies in our laboratory. Indeed, it has been shown that inactivated CVB4 can stimulate the production of IL-6, TNF $\alpha$ and IL-12 by monocytes [15], which suggests that a replicative infection of monocytes/macrophages by the virus is not mandatory for inducing inflammation. 
In GM-CSF MDM inoculated with CVB4, a low level of viral RNA was detected by sensitive real-time RT-qPCR, but was not associated with the presence of IFN $\alpha$ in supernatants, suggesting that the infection was at a very low level in these cells or was abortive. This hypothesis is in agreement with the demonstration by another team that HIV replication was suppressed in GM-CSF-induced macrophages, but not in M-CSF-induced macrophages [38]. A similar finding was also reported for Mycobacterium tuberculosis, another intracellular pathogen [34].

M-CSF MDM were infected with CVB4, whereas monocytes were infected when the virus was mixed with human non-neutralizing serum. In addition, no enhancement of CVB4 infection (i.e., no increase in FN $\alpha$ or intracellular viral RNA) was obtained in MDM when the virus was mixed with serum, although both monocytes and MDM were reported to express Fc $\gamma$ RI and Fc $\gamma$ RII [34]. Thus, this suggests that antibodies do not enhance the infection of M-CSF-induced MDM with CVB4.

The investigation of CVB4 persistence in M-CSF-induced MDM displayed that significant levels of infectious particles in supernatants and viral intracellular RNA can be detected up to 12 days (end of the culture), while the cellular response, especially the production of IFN $\alpha$, was limited to early steps (Day 3). This finding suggests that CVB4 probably overrides the cellular response to establish persistence in MDM. Further studies are needed to understand the mechanisms of interaction between CVB4 and macrophages.

The micro-environment and the phenotype highly impact the physiology of macrophages. Therefore, the relationship between CVB4 and these cells in the pathogenesis of autoimmune diseases, such as T1D, can depend on a specific micro-environment. Indeed, for example, it has been suggested that GM-CSF plays a role in maintaining macrophage populations in a physiological steady state and in controlling the development of autoimmune diseases by regulating the immune response and the immunological tolerance [39].

Whether the phenotype of macrophages recruited in pancreas plays a role in interactions with $\mathrm{CVB}$ and in the development of autoimmunity deserves further investigation.

In conclusion, human primary M-CSF-induced MDM, but not GM-CSF-induced MDM, can be infected by CVB4. A productive infection can be obtained, and the virus can persist in these cells. An inflammatory reaction of the cells is observed during the acute phase of the infection. Macrophages can then be considered not only as target cells, but also as reservoirs for CVB4 in tissues, with implications in the pathogenesis of chronic diseases triggered by these viruses.

\section{Materials and Methods}

\subsection{Virus Stocks}

CVB4 E2, the diabetogenic strain of coxsackievirus B4, was used in all experiments. It was kindly provided by Ji-Won Yoon (Julia McFarlane Diabetes Research Center, Calgary, Alberta, Canada) and was propagated in Hep-2 cells (BioWhittaker, Walkersville, MD, USA).

\subsection{Peripheral Blood Monocyte-Derived Macrophages}

Human blood collected from healthy donors was obtained at the Regional Blood Bank (Lille, France). This study was conducted in accordance with the rules of the Declaration of Helsinki of 1975, revised in 2008. Written consent was obtained from donors by the blood bank, and they were informed that the blood would be used for research purposes.

Peripheral blood mononuclear cells (PBMCs) were isolated from buffy coats by density gradient centrifugation using Ficoll-Hypaque ${ }^{\mathrm{TM}}$ PLUS (GE Healthcare, Vélizy-Villacoublay, France), as described previously [15]. Cells were resuspended in non-supplemented RPMI 1640 medium, and an average of $10^{7}$ cells per well $\left(\sim 1.5\right.$ million $\left./ \mathrm{cm}^{2}\right)$ was seeded in a Falcon $\AA$ polystyrene six-well plate (Fischer Scientific, Illkirch-Graffenstaden, France). Monocytes from the PBMCs were allowed to adhere to plastic for $2 \mathrm{~h}$ at $37^{\circ} \mathrm{C}, 5 \% \mathrm{CO} 2$, and non-adherent cells were subsequently removed by aspiration and extensive washing with PBS. Monocytes were cultivated in serum-free medium 
(SFM) containing either macrophage colony-stimulating factor (M-CSF) or granulocyte-macrophage colony-stimulating factor (GM-CSF) (Peprotech, Neuilly-sur-Seine, France) at $20 \mathrm{ng} / \mathrm{mL}$. The medium was changed on Day 3. On Day 7, the cells were differentiated into macrophages. All media were purchased from Gibco® (Thermo Fischer Scientific, Villebon sur Yvette, France).

\subsection{Human Serum}

Whole blood was centrifugated at $2500 \mathrm{rpm}$ for $15 \mathrm{~min}$, and serum was aliquoted and stored at $-20{ }^{\circ} \mathrm{C}$. The level of anti-CVB4 antibodies was determined by the seroneutralization assay, as previously described [15]. Serum with a titer of 256 was used in all experiments.

\subsection{May-Grunwald-Giemsa Staining and Immunocytochemistry}

MDM were detached from the plates by incubation at $4{ }^{\circ} \mathrm{C}$ with PBS containing $5 \mathrm{mM}$ EDTA followed by gentle scraping. Then, cells were plated on a slide by cytocentrifugation at $500 \mathrm{rpm}$ for $5 \mathrm{~min}$, and slides were air dried. Cells intended for May-Grunwald-Giemsa (MGG) staining were fixed with ethanol for $5 \mathrm{~min}$ and stained using the automated SP-10 ${ }^{\mathrm{TM}}$ slide maker/stainer (Sysmex, Villepinte, France). For immunocytochemistry purposes, cells were fixed with acetone for $10 \mathrm{~min}$. The FLEX monoclonal mouse anti-human CD68 (clone KP1) antibody was purchased from Dako (Dako, Les Ulis, France), and anti-CD163 monoclonal antibody was supplied by DB Biotech (Kosice, Slovak Republic). The staining was performed using the Ultra View Universal DAB Detection Kit, on the VENTANA@ Benchmark XT fully-automated IHC/ISH staining instrument (Roche Diagnostics, Meylan, France).

\subsection{Flow Cytometry}

Monoclonal antibodies directed against human surface markers CD14, CD80, CD83, CD86, CCR7 (Beckman Coulter, Villepinte, France) and HLA-DR (Becton Dickinson Bioscience, Le Pont-de-Claix, France) were used at the supplier's recommended concentrations. The CD14 antibody was fluorescein isothiocyanate (FITC)-conjugated, whereas CD80, CD83, CD86, CCR7 and HLA-DR antibodies were phycoerythrin (PE)-conjugated. Monocytes and monocyte-derived cells were detached and washed once in PBS. Cell suspensions were incubated at $4{ }^{\circ} \mathrm{C}$ for 20 min with the appropriate antibodies. The cells were then fixed in $0.5 \%$ paraformaldehyde, washed once with PBS and analyzed by flow cytometry on a Navios Flow cytometer (Beckman Coulter, Inc.).

\subsection{Quantification of Cytokines}

IFN $\alpha$ was measured using the IFN $\alpha$ pan-specific ELISA kit (Mabtech $\AA$, Sophia Antipolis, France) that allowed detection of subtypes $1 / 13,2,4,5,6,7,8,10,14,16$ and 17 of IFN $\alpha$. TNF $\alpha$, IL- 6 and IL-10 were quantified with ELISA kits purchased from Peprotech $\AA$. Assays were performed according to the manufacturer's instructions. The detection ranges were $7-700 \mathrm{pg} / \mathrm{mL}$ (IFN $\alpha)$, 23-1500 pg/mL (TNF $\alpha), 32-2000$ pg/mL (IL-6) and 32-2000 pg/mL (IL-10).

\subsection{Viral Progeny}

The viral titer in supernatants of infected cells was assessed using the end-point dilution assay, and the Spearman-Karber statistical method was used to determine the tissue culture $50 \%$ infectious dose $\left(\mathrm{TCID}_{50}\right)$.

\subsection{RNA Extraction}

Cells were previously collected in TriReagent $\left(\mathrm{B}\right.$ for cell lysis and stored at $-80{ }^{\circ} \mathrm{C}$ until RNA extraction. For the extraction of RNA from supernatants, a volume of $250 \mu \mathrm{L}$ was used. Total RNA was extracted using the TriReagent ${ }^{\circledR}$ RNA isolation reagent/chloroform procedure (Sigma-Aldrich). 


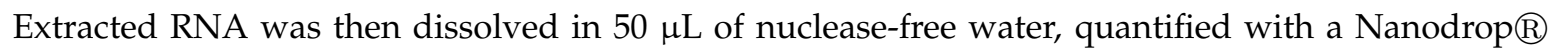
spectrophotometer (Thermo Fischer Scientific).

\subsection{DNase Treatment}

A DNA enzymatic digestion was performed on RNA extracts. A volume of $10 \mu \mathrm{L}$ of RNA was mixed in a tube with $2 \mu \mathrm{L}$ of DNase RDD10 $\times$ buffer (Qiagen, Les Ulis, France), $0.2 \mu \mathrm{L}$ of DNase I (Qiagen), $0.25 \mu \mathrm{L}$ of RNase inhibitor (Invitrogen/Thermofischer Scientific) and $7.55 \mu \mathrm{L}$ of nuclease-free water. The tube was incubated at $37^{\circ} \mathrm{C}$ for $30 \mathrm{~min}$ and at $65^{\circ} \mathrm{C}$ for $5 \mathrm{~min}$. The tube was brought to $4{ }^{\circ} \mathrm{C}$ and then vortexed.

\subsection{Enterovirus Real-Time Quantitative PCR}

The Affinityscript ${ }^{\circledR}$ QPCR cDNA Synthesis Kit (Agilent, Les Ulis, France) was used for the RNA retro-transcription step on a Perkin Elmer 2400 thermocycler. Quantitative RT-PCR for cDNA amplification was performed with the Brilliant II $\AA$ QPCR Kit (Agilent) on the Mx3000p® (Stratagene/ Thermofischer Scientific). Oligonucleotides and RT-PCR conditions were previously described [15]. Enterovirus 71 RNA (Vircell, Granada, Spain) was used as the standard for quantification.

\subsection{Quantification of Coxsackie and Adenovirus Receptor $m R N A$}

CAR mRNA was quantified by real-time RT-qPCR using the SuperScript III Platinum One-Step Quantitative RT-PCR System (Life Technologies/Thermofischer Scientific). The oligonucleotides were already published [40]. The quantification was carried out on the Mx3000p $\AA$ (Stratagene) with the following program: $50^{\circ} \mathrm{C}$ for $15 \mathrm{~min}, 95^{\circ} \mathrm{C}$ for $2 \mathrm{~min}$ and 40 cycles of amplification consisting of $15 \mathrm{~s}$ at $95^{\circ} \mathrm{C}$ and $30 \mathrm{~s}$ at $60^{\circ} \mathrm{C}$. The expression of the beta-actin gene was used for normalization. CAR mRNA relative expression in macrophages as compared to parental monocytes was determined with the $2^{-\Delta \Delta C t}$ formula [41].

\subsection{Statistical Analysis}

Data were presented as the mean \pm SEM. Graphs and analyses were performed with GraphPad Prism $\AA$ V6.0 software. Comparisons were performed with the Mann-Whitney $U$ test with the significance set at 0.05 .

Acknowledgments: This work was supported by Ministère de l'Education Nationale de la Recherche et de la Technologie, Université Lille 2 (Equipe d'accueil 3610) and Centre Hospitalier Régional et Universitaire de Lille, as well as by EU FP7 (GA-261441-PEVNET: Persistent virus infection as a cause of pathogenic inflammation in type 1 diabetes-an innovative research program of biobanks and expertise). The authors thank Antoine Bertin and Magloire Nekoua for technical assistance.

Author Contributions: E.K.A. and D.H. conceived of and designed the experiments. E.K.A. performed the experiments and analyzed the data. F.S., J.T. and M.C.C. contributed to performing of the experiments. E.K.A. and D.H. wrote the paper.

Conflicts of Interest: The authors declare no conflict of interest. The funding sponsors had no role in the design of the study; in the collection, analyses nor interpretation of data; in the writing of the manuscript nor in the decision to publish the results.

\section{References}

1. Knowles, N.; Hovi, T; Hyypiä, T.; King, A.M.Q.; Lindberg, A.M.; Pallansch, M.A.; Palmenberg, A.C.; Simmonds, P.; Skern, T.; Stanway, G.; et al. Picornaviridae. In Virus Taxonomy: Classification and Nomenclature of Viruses: Ninth Report of the International Committee on Taxonomy of Viruses; King, A.M.Q., Adams, M.J., Carstens, E.B., Lefkowitz, E.J., Eds.; Publisher: San Diego, CA, USA, 2012; pp. 855-880.

2. Tapparel, C.; Siegrist, F.; Petty, T.J.; Kaiser, L. Picornavirus and enterovirus diversity with associated human diseases. Infect. Genet. Evol. J. Mol. Epidemiol. Evol. Genet. Infect. Dis. 2013, 14, 282-293. [CrossRef] [PubMed] 
3. Romero, J.R. Pediatric group B coxsackievirus infections. Curr. Top. Microbiol. Immunol. 2008, 323, $223-239$. [PubMed]

4. Hober, D.; Alidjinou, E.K. Enteroviral pathogenesis of type 1 diabetes: Queries and answers. Curr. Opin. Infect. Dis. 2013, 26, 263-269. [CrossRef] [PubMed]

5. Hober, D.; Sauter, P. Pathogenesis of type 1 diabetes mellitus: Interplay between enterovirus and host. Nat. Rev. Endocrinol. 2010, 6, 279-289. [CrossRef] [PubMed]

6. Yin, H.; Berg, A.-K.; Tuvemo, T.; Frisk, G. Enterovirus RNA is found in peripheral blood mononuclear cells in a majority of type 1 diabetic children at onset. Diabetes 2002, 51, 1964-1971. [CrossRef] [PubMed]

7. Schulte, B.M.; Bakkers, J.; Lanke, K.H.W.; Melchers, W.J.G.; Westerlaken, C.; Allebes, W.; Aanstoot, H.-J.; Bruining, G.J.; Adema, G.J.; van Kuppeveld, F.J.M.; et al. Detection of enterovirus RNA in peripheral blood mononuclear cells of type 1 diabetic patients beyond the stage of acute infection. Viral Immunol. 2010, 23, 99-104. [CrossRef] [PubMed]

8. Toniolo, A.; Maccari, G.; Federico, G.; Salvatoni, A.; Bianchi, G.; Baj, A. Are enterovirus infections linked to the early stages of Type 1 diabetes? Abstract. In Proceedings of the American Society of Microbiology Meeting, San Diego, CA, USA, 23-27 May 2010.

9. Salvatoni, A.; Baj, A.; Bianchi, G.; Federico, G.; Colombo, M.; Toniolo, A. Intrafamilial spread of enterovirus infections at the clinical onset of type 1 diabetes. Pediatr. Diabetes 2013, 14, 407-416. [CrossRef] [PubMed]

10. Alidjinou, E.K.; Chehadeh, W.; Weill, J.; Vantyghem, M.-C.; Stuckens, C.; Decoster, A.; Hober, C.; Hober, D. Monocytes of patients with type 1 diabetes harbour enterovirus RNA. Eur. J. Clin. Investig. 2015, 45, 918-924. [CrossRef] [PubMed]

11. Hober, D.; Chehadeh, W.; Bouzidi, A.; Wattré, P. Antibody-dependent enhancement of coxsackievirus B4 infectivity of human peripheral blood mononuclear cells results in increased interferon- $\alpha$ synthesis. J. Infect. Dis. 2001, 184, 1098-1108. [CrossRef] [PubMed]

12. Goffard, A.; Alidjinou, E.K.; Sané, F.; Choteau, L.; Bouquillon, C.; Caloone, D.; Lobert, P.E.; Hober, D. Antibodies enhance the infection of phorbol-ester-differentiated human monocyte-like cells with coxsackievirus B4. Microbes Infect. Inst. Pasteur 2013, 15, 18-27. [CrossRef] [PubMed]

13. Hober, D.; Chehadeh, W.; Weill, J.; Hober, C.; Vantyghem, M.-C.; Gronnier, P.; Wattré, P. Circulating and cell-bound antibodies increase coxsackievirus B4-induced production of IFN- $\alpha$ by peripheral blood mononuclear cells from patients with type 1 diabetes. J. Gen. Virol. 2002, 83, 2169-2176. [CrossRef] [PubMed]

14. Chehadeh, W.; Lobert, P.-E.; Sauter, P.; Goffard, A.; Lucas, B.; Weill, J.; Vantyghem, M.-C.; Alm, G.; Pigny, P.; Hober, D. Viral protein VP4 is a target of human antibodies enhancing coxsackievirus B4- and B3-induced synthesis of alpha interferon. J. Virol. 2005, 79, 13882-13891. [CrossRef] [PubMed]

15. Alidjinou, E.K.; Sané, F.; Engelmann, I.; Hober, D. Serum-dependent enhancement of coxsackievirus B4-induced production of IFN $\alpha$, IL-6 and TNF $\alpha$ by peripheral blood mononuclear cells. J. Mol. Biol. 2013, 425, 5020-5031. [CrossRef] [PubMed]

16. Shi, C.; Pamer, E.G. Monocyte recruitment during infection and inflammation. Nat. Rev. Immunol. 2011, 11, 762-774. [CrossRef] [PubMed]

17. Murray, P.J.; Wynn, T.A. Protective and pathogenic functions of macrophage subsets. Nat. Rev. Immunol. 2011, 11, 723-737. [CrossRef] [PubMed]

18. Tsunetsugu-Yokota, Y.; Akagawa, K.; Kimoto, H.; Suzuki, K.; Iwasaki, M.; Yasuda, S.; Häusser, G.; Hultgren, C.; Meyerhans, A.; Takemori, T. Monocyte-derived cultured dendritic cells are susceptible to human immunodeficiency virus infection and transmit virus to resting $\mathrm{T}$ cells in the process of nominal antigen presentation. J. Virol. 1995, 69, 4544-4547. [PubMed]

19. De Graaff, P.M.A.; de Jong, E.C.; van Capel, T.M.; van Dijk, M.E.A.; Roholl, P.J.M.; Boes, J.; Luytjes, W.; Kimpen, J.L.L.; van Bleek, G.M. Respiratory syncytial virus infection of monocyte-derived dendritic cells decreases their capacity to activate CD4 T cells. J. Immunol. 2005, 175, 5904-5911. [CrossRef] [PubMed]

20. Le Nouën, C.; Munir, S.; Losq, S.; Winter, C.C.; McCarty, T.; Stephany, D.A.; Holmes, K.L.; Bukreyev, A.; Rabin, R.L.; Collins, P.L.; et al. Infection and maturation of monocyte-derived human dendritic cells by human respiratory syncytial virus, human metapneumovirus, and human parainfluenza virus type 3. Virology 2009, 385, 169-182. [CrossRef] [PubMed] 
21. Rawle, D.J.; Setoh, Y.X.; Edmonds, J.H.; Khromykh, A.A. Comparison of attenuated and virulent West Nile virus strains in human monocyte-derived dendritic cells as a model of initial human infection. Virol. J. 2015, 12, 46. [CrossRef] [PubMed]

22. Kramer, M.; Schulte, B.M.; Toonen, L.W.J.; de Bruijni, M.A.M.; Galama, J.M.D.; Adema, G.J.; van Kuppeveld, F.J.M. Echovirus infection causes rapid loss-of-function and cell death in human dendritic cells. Cell. Microbiol. 2007, 9, 1507-1518. [CrossRef] [PubMed]

23. Schulte, B.M.; Kers-Rebel, E.D.; Prosser, A.C.; Galama, J.M.D.; van Kuppeveld, F.J.M.; Adema, G.J. Differential susceptibility and response of primary human myeloid BDCA1(+) dendritic cells to infection with different Enteroviruses. PLoS ONE 2013, 8, e62502. [CrossRef] [PubMed]

24. Mosser, D.M.; Edwards, J.P. Exploring the full spectrum of macrophage activation. Nat. Rev. Immunol. 2008, 8, 958-969. [CrossRef] [PubMed]

25. Willcox, A.; Richardson, S.J.; Bone, A.J.; Foulis, A.K.; Morgan, N.G. Analysis of islet inflammation in human type 1 diabetes. Clin. Exp. Immunol. 2009, 155, 173-181. [CrossRef] [PubMed]

26. Gong, X.; Zhou, J.; Zhu, W.; Liu, N.; Li, J.; Li, L.; Jin, Y.; Duan, Z. Excessive proinflammatory cytokine and chemokine responses of human monocyte-derived macrophages to enterovirus 71 infection. BMC Infect. Dis. 2012, 12, 224. [CrossRef] [PubMed]

27. McElroy, A.K.; Nichol, S.T. Rift Valley fever virus inhibits a pro-inflammatory response in experimentally infected human monocyte derived macrophages and a pro-inflammatory cytokine response may be associated with patient survival during natural infection. Virology 2012, 422, 6-12. [CrossRef] [PubMed]

28. Wati, S.; Li, P.; Burrell, C.J.; Carr, J.M. Dengue virus (DV) replication in monocyte-derived macrophages is not affected by tumor necrosis factor alpha (TNF- $\alpha$ ), and DV infection induces altered responsiveness to TNF-alpha stimulation. J. Virol. 2007, 81, 10161-10171. [CrossRef] [PubMed]

29. Sauter, P.; Lobert, P.-E.; Lucas, B.; Varela-Calvino, R.; Alm, G.; Wattre, P.; Hober, D. Role of the capsid protein VP4 in the plasma-dependent enhancement of the Coxsackievirus B4E2-infection of human peripheral blood cells. Virus Res. 2007, 125, 183-190. [CrossRef] [PubMed]

30. Byrd, D.; Shepherd, N.; Lan, J.; Hu, N.; Amet, T.; Yang, K.; Desai, M.; Yu, Q. Primary human macrophages serve as vehicles for vaccinia virus replication and dissemination. J. Virol. 2014, 88, 6819-6831. [CrossRef] [PubMed]

31. Jaguin, M.; Houlbert, N.; Fardel, O.; Lecureur, V. Polarization profiles of human M-CSF-generated macrophages and comparison of M1-markers in classically activated macrophages from GM-CSF and M-CSF origin. Cell. Immunol. 2013, 281, 51-61. [CrossRef] [PubMed]

32. Rey-Giraud, F.; Hafner, M.; Ries, C.H. In vitro generation of monocyte-derived macrophages under serum-free conditions improves their tumor promoting functions. PLoS ONE 2012, 7, e42656. [CrossRef] [PubMed]

33. Akagawa, K.S. Functional heterogeneity of colony-stimulating factor-induced human monocyte-derived macrophages. Int. J. Hematol. 2002, 76, 27-34. [CrossRef] [PubMed]

34. Akagawa, K.S.; Komuro, I.; Kanazawa, H.; Yamazaki, T.; Mochida, K.; Kishi, F. Functional heterogeneity of colony-stimulating factor-induced human monocyte-derived macrophages. Respirology 2006, 11, S32-S36. [CrossRef] [PubMed]

35. Bellora, F.; Castriconi, R.; Dondero, A.; Reggiardo, G.; Moretta, L.; Mantovani, A.; Moretta, A.; Bottino, C. The interaction of human natural killer cells with either unpolarized or polarized macrophages results in different functional outcomes. Proc. Natl. Acad. Sci. USA 2010, 107, 21659-21664. [CrossRef] [PubMed]

36. Geissmann, F.; Manz, M.G.; Jung, S.; Sieweke, M.H.; Merad, M.; Ley, K. Development of monocytes, macrophages, and dendritic cells. Science 2010, 327, 656-661. [CrossRef] [PubMed]

37. Patel, K.P.; Coyne, C.B.; Bergelson, J.M. Dynamin- and lipid raft-dependent entry of decay-accelerating factor (DAF)-binding and non-DAF-binding coxsackieviruses into nonpolarized cells. J. Virol. 2009, 83, 11064-11077. [CrossRef] [PubMed]

38. Matsuda, S.; Akagawa, K.; Honda, M.; Yokota, Y.; Takebe, Y.; Takemori, T. Suppression of HIV replication in human monocyte-derived macrophages induced by granulocyte/macrophage colony-stimulating factor. AIDS Res. Hum. Retrovir. 1995, 11, 1031-1038. [CrossRef] [PubMed]

39. Bhattacharya, P.; Thiruppathi, M.; Elshabrawy, H.A.; Alharshawi, K.; Kumar, P.; Prabhakar, B.S. GM-CSF: An immune modulatory cytokine that can suppress autoimmunity. Cytokine 2015, 75, 261-271. [CrossRef] [PubMed] 
40. Lam, W.Y.; Cheung, A.C.Y.; Tung, C.K.C.; Yeung, A.C.M.; Ngai, K.L.K.; Lui, V.W.Y.; Chan, P.K.S.; Tsui, S.K.W. miR-466 is putative negative regulator of Coxsackie virus and Adenovirus Receptor. FEBS Lett. 2015, 589, 246-254. [CrossRef] [PubMed]

41. Livak, K.J.; Schmittgen, T.D. Analysis of relative gene expression data using real-time quantitative PCR and the $2^{-\Delta \Delta C t}$ Method. Methods 2001, 25, 402-408. [CrossRef] [PubMed] Attribution (CC-BY) license (http://creativecommons.org/licenses/by/4.0/). 